\title{
Kinetic and Spectroscopic Characterization of the Isomers of the Allyl Bromide Molecular Ion
}

\author{
Tino Gäumann and Zhiqing Zhu \\ Institute of Physical Chemistry, Federal School of Technology, Lausanne, Switzerland
}

\author{
Marcia C. Kida and José M. Riveros \\ Institute of Chemistry, University of São Paulo, São Paulo, Brazil
}

\begin{abstract}
The kinetics of the ion/molecule reactions of the molecular ion of allyl bromide (3bromopropene), $\mathrm{C}_{3} \mathrm{H}_{5} \mathrm{Br}^{+} \cdot$, with its neutral show that only $(82 \pm 2) \%$ of these ions are reactive. This percentage is mildly sensitive to ionization energy below $13 \mathrm{eV}$, but is pressure insensitive. The collisionless infrared multiphoton-induced photofragmentation of these ions at $10.25 \mu \mathrm{m}$ and at variable power densities is consistent with the presence of two ionic species in the ratio obtained from the kinetic experiments. The most abundant species undergoes much faster photofragmentation at this wavelength, but at $10.59 \mu \mathrm{m}$ the photofragmentation rates become comparable. Experiments performed by isolating the remaining molecular ions after completion of the ion/molecule reaction confurm that the unreactive species corresponds to the slow photodissociating ion at $10.25 \mu \mathrm{m}$. A combination of kinetic experiments and photodissociation is used to establish that the less abundant species behaves unlike the molecular ion obtained from 1-bromopropene, 2-bromopropene, or bromocyclopropane. The two structures for the molecular ion are shown to originate from ionization and not by isomerization through collisions. (J Am Soc Mass Spectrom 1991, $2,372-378)$
\end{abstract}

$\mathrm{T}$ The elucidation of the structure of gas-phase ions has been one of the major challenges that stems from the early days of mass spectrometry. Unlike stable neutral molecules, few spectroscopic techniques are yet available that can be routinely applied to obtain direct information on ion structures. While several impressive developments have taken place in the last few years [1], formidable problems remain at large before polyatomic ions can become amenable to such techniques.

Semi-empirical and ab initio methods at increasing levels of sophistication have become very important in the assignment of likely ionic structures [2]. This has resulted in a lively interplay between theoretical calculations and experiment to an extent probably unrivaled in other areas of present day chemistry [3]. On the experimental side, collision-induced dissociation of ions [4] has been used extensively to establish the chemical connectivity of the atoms in the ion structure, but obviously yields no details about particular geometric parameters. This method can also be useful to infer the presence of isomeric ionic struc-

Address reprint requests to Tino Gäumann, Institute of Physical Chemistry, EPFL Ecublens, 1015 Lausanne, Switzerland tures [5-7]. The thermochemical stability of ions has emerged from a wide range of mass spectrometric techniques [8] and is of paramount importance in establishing likely ionic structures and in assessing the reliability of theoretical predictions.

One of the most striking features of ion structures is the fact that electron impact ionization can often give rise to a mixture of isomeric ions. This is due to the high energy content of the ionizing electrons but also to the low barriers frequently encountered for interconversion among ion structures. While hydrocarbon ions are notoriously well illustrated in this respect (see, for example, ref 5 for the classical case of $\mathrm{C}_{7} \mathrm{H}_{7}^{+}$), recent interest has been generated by the observation that simple organic ions, like $\mathrm{CH}_{3} \mathrm{OH}^{+}$, can exist in unusual structures, i.e., $\left(\mathrm{CH}_{2} \mathrm{OH}_{2}\right)^{+}$, for which the corresponding neutral is either not in a local minimum in the energy surface, or is very reactive $[9,10]$. The characterization of these species as distonic ions has becn thoroughly reviewed by Hammerum [11]. Another category of ionic species that may have to be considered in some cases are moieties that are best described as ion-neutral complexes. For example, the results of the dynamics of the dissociation of energy-selected molecular ions of propanol 
point out the participation of stable ion/dipole complexes, i.e., $\mathrm{C}_{3} \mathrm{H}_{6}^{+} \cdot\left(\mathrm{OH}_{2}\right)$, along the reaction coordinate for fragmentation [12]. Several cases by now have been illustrated where fragmentation is likely to be mediated by formation of an ion/neutral complex [13]. It is thus clear that the subject of ion structures is indeed very rich and much in demand to describe properly the energetics and dynamics of unimolecular and bimolecular processes of ions.

The formation of isomeric ions upon ionization and/or fragmentation can also be established in several cases by differences in ion/molecule reactivity. This approach is very effective when one of the isomers is unreactive, as is the case for $\mathrm{C}_{7} \mathrm{H}_{7}^{+}$ions [14] and $\mathrm{C}_{3} \mathrm{H}_{3}^{+}$ions [15]. A more elegant and potentially powerful technique to distinguish isomeric ions is through photodissociation spectroscopy involving single or multiphoton processes induced by infrared (IR) or visible radiation $[16,17]$. Several cases have already been illustrated based on differences in spectra $[18,19]$ or on photofragmentation kinetics [20-23].

This article describes the identification of two distinct isomers for the molecular ion of 3-bromopropene (allyl bromide) generated by electron impact. These isomers are shown to differ in their ion/molecule reactivity and in their photofragmentation kinetics. In an earlier study, Riveros and Galembeck [24] described the ion/molecule chemistry of the 3-bromopropene ion with its neutral precursor

$$
\mathrm{C}_{3} \mathrm{H}_{5} \mathrm{Br}^{+}+\mathrm{H}_{2} \mathrm{C}=\mathrm{CHCH}_{2} \mathrm{Br} \rightarrow \mathrm{C}_{6} \mathrm{H}_{9}^{+}+\mathrm{HBr}+\mathrm{Br} \cdot
$$

Likewise, the infrared multiphoton dissociation spectra of the molecular ions, $\mathrm{C}_{3} \mathrm{H}_{5} \mathrm{Br}^{+}$., generated from 1-bromopropene, 2-bromopropene, 3-bromopropene, and bromocyclopropane have revealed that these ions have a distinct IR spectra in the 9.2 to 10.7 $\mu \mathrm{m}$ region when probed with a $\mathrm{CO}_{2}$ laser [25]. The multipholon process promotes the fragmentation of the molecular ion according to reaction 2.

$$
\mathrm{C}_{3} \mathrm{H}_{5} \mathrm{Br}^{+} \cdot+n h v_{\mathrm{IR}} \rightarrow \mathrm{C}_{3} \mathrm{H}_{5}^{+}+\mathrm{Br} \text {. }
$$

A more detailed analysis of the kinetic curves for processes 1 and 2 reveals a more complex situation than previously reported and points out to the presence of two isomeric species for the allyl bromide parent ion.

\section{Experimental Section}

The kinetics of the ion/molecule reactions of allyl bromide were carried out in two different Fourier transform ion cyclotron resonance spectrometers. Most of the experiments involved a homemade instrument using a cubic cell, a fixed magnetic field of $1.4 \mathrm{~T}$, and a Nicolet FTMS-1000 data system (Madison, WI).
In this spectrometer ions were generated by electron impact at ionization energies ranging from 11 to 70 $\mathrm{eV}$, and the molecular ions $\mathrm{C}_{3} \mathrm{H}_{5}^{79} \mathrm{Br}^{+}$. and $\mathrm{C}_{3} \mathrm{H}_{5}^{81} \mathrm{Br}^{+}$. were isolated after ionization by removing all other primary ions with an ejection pulse tailored by the SWIFT technique [26]. The second instrument used a Spectrospin FTMS Data System (Fällanden, Switzerland), a cylindrical cell, and a magnetic field of 4.7 T. In this system the disappearance of the molecular ion was followed without ejection of any ions and each data point was collected in the single line mode. Typical operating pressures were in the range of 4-6 $\times 10^{-8}$ mbar (uncorrected ionization gauge reading), and data points were collected at intervals of $200 \mathrm{~ms}$ trapping time up to a total of 8 to $10 \mathrm{~s}$.

Photodissociation experiments were carried out as previously described [25] in the Nicolet controlled Fourier transform (FT) spectrometer. The high vacuum chamber inside the magnetic field was fitted with optical windows on opposite sides that allowed for irradiation either by an $\mathrm{Ar}^{+}$laser or a $\mathrm{CO}_{2}$ laser through oblong holes drilled in the cell plates perpendicular to the laser beam. The pressure of the 3bromopropene was maintained constant typically in the range of 4-6 $\times 10^{-9}$ mbar and the selection of the molecular ion was carried out as above. Experiments were carried out mostly at $70 \mathrm{eV}$ ionization energy but no significant differences could be encountered in the photofragmentation kinetics at lower ionization energies. These experiments were carried out by trapping the ions for variable periods of time while laser irradiation times were controlled by a mechanical shutter triggered by the normal sequence of an FT experiment: ion quench, ionization, ion selection, laser irradiation, chirp excitation, and detection. High trapping voltages $(3 \mathrm{~V})$ were used in these experiments to concentrate the ions along the center portion of the cell in order to optimize the overlap of the laser beam with the ion cloud. Each data point represents an average of 100 scans. In the experiments with the infrared laser, a 5-s delay time was used between successive laser shots to minimize any possible heating effects of the ion source at the longer irradiation times. These times were typically varied between 10 $\mathrm{ms}$ and up to approximately $1.5 \mathrm{~s}$ for the experiments at low laser powers.

The 3-bromopropene and 1-bromopropene samples used throughout the work were purified by gas chromatography. The results reported below were similar for the three independent inlet systems used over a period of 1 year.

\section{Results and Discussion}

Mass spectra taken at variable reaction times after isolation of $\mathrm{C}_{3} \mathrm{H}_{5} \mathrm{Br}^{+}$. confirm that reaction 1 is the only ion/molecule reaction of the molecular ion of 3-bromopropene. A typical set of data for the disappearance of the molecular ion is shown in Figure 1. 


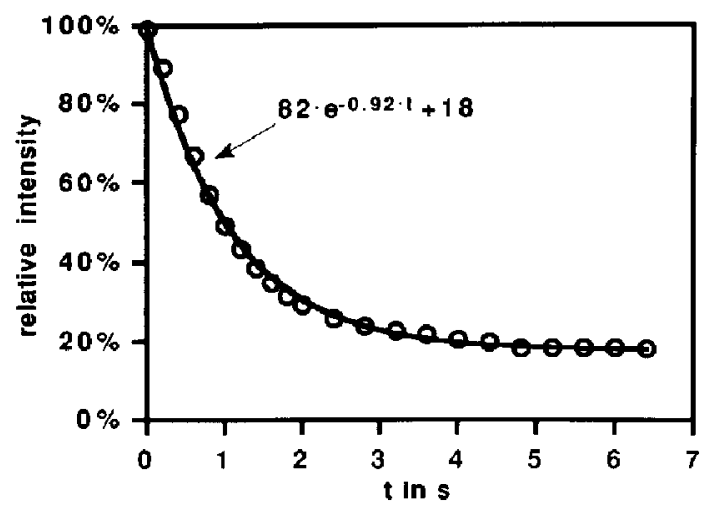

Figure 1. Time plot of the decay of the normalized ion intensity of the molecular ions of 3-bromopropene revealing reaction 1 and the unreactive population of inns at a pressure of $5.1 \times$ $10^{-8}$ mbar.

Two aspects deserve particular attention in these data: (1) a rate constant can be readily calculated from this time decay by calibrating the ion gauge pressure [27]; and (2) the molecular ion population reaches a nonzero constant value after 5 to $6 \mathrm{~s}$ of reaction time at the pressures used for the kinetic experiments. This latter observation is associated with the presence of an unreactive ionic species. The population of the unreactive molecular ions has been measured to be $(18 \pm$ 2)\% of the total initial molecular ion concentration at electron energies above $15 \mathrm{eV}$. This behavior and this value are observed in both spectrometers. At lower electron energies there is a marked decrease of the unreactive species as shown in Figure 2, where the remaining fraction of molecular ions after $6 \mathrm{~s}$ of reaction at $6.3 \times 10^{-9}$ mbar is plotted as a function of nominal electron energy.

The variation at low ionization energies of the unreactive population of the molecular ions of 3bromopropene strongly suggests that the two species originate from ions with different structures and/or internal energies. However, the extremely low energy threshold for fragmentation of the molecular ion precludes the existence of ions with much internal energy:

$$
\mathrm{C}_{3} \mathrm{H}_{5} \mathrm{Br}^{+} \cdot \rightarrow \mathrm{C}_{3} \mathrm{H}_{5}^{+}+\mathrm{Br} \cdot \Delta \mathrm{H}_{298}=39 \mathrm{~kJ} \cdot \mathrm{mol}^{-1}
$$

A second alternative is to consider different electronic states of the molecular ion. The photoelectron spectrum of 3-bromopropene reveals the ground state to correspond to removal of a $\pi$ electron with the components of the doublet originating from removal of the $p$ electron of the $\mathrm{Br}$ only $0.37 \mathrm{eV}$ higher up in energy [28]. The idea of large changes in reactivity originating from different electronic states is a fascinating subject but it requires the presence of an unusually long-lived metastable electronic state capable of surviving the long reaction times of ion/molecule reactions in the ion cyclotron resonance cell.

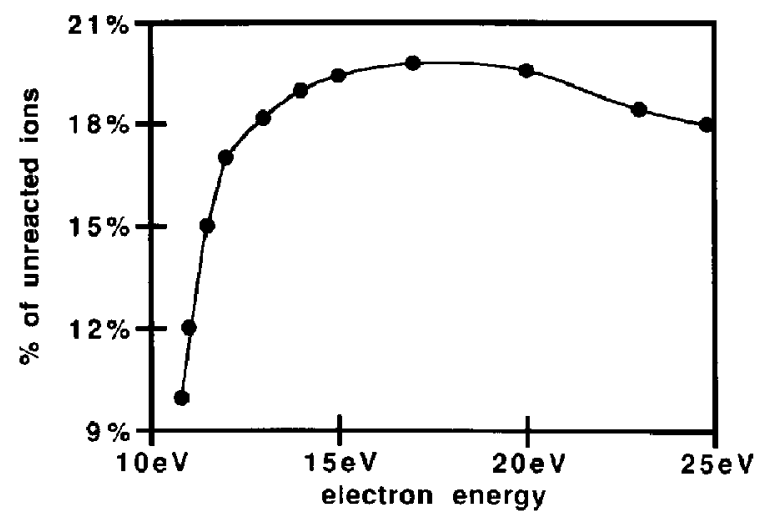

Figure 2. Percentage of unreactive molecular ions of 3-bromopropene as a function of nominal electron energy (pressure of $6.3 \times 10^{8}$ mbar).

The most likely source of differences in reactivity to be considered is the presence of two or more isomeric species. In the present case, isomeric species can arise from different molecular ions or from an isomerization induced by a 1,3 hydrogen shift to yield the 1-bromopropene cation.

$$
\begin{gathered}
\left(\mathrm{H}_{2} \mathrm{C}=\mathrm{CHCH}_{2} \mathrm{Br}\right)^{+} \cdot \rightarrow\left(\mathrm{BrHC}=\mathrm{CHCH}_{3}\right)^{+} . \\
\Delta \mathrm{H}=-80 \mathrm{~kJ} \cdot \mathrm{mol}^{-1}
\end{gathered}
$$

This latter possibility is particularly attractive because the 1-bromopropene cation has been shown to be unreactive [27]. The barrier for such an isomerization is not known; however, the above process can only become feasible if such a barrier is substantially lower than the $39 \mathrm{~kJ} \cdot \mathrm{mol}^{-1}$ required for fragmentation of the molecular ion. If the barrier were to be this low one might expect an even larger fraction of unreactive ions because the 1-bromopropene cation is substantially lower in energy. The alternative 2-bromopropene or bromocyclopropane cations can be ruled out based on experiments in which these ions are allowed to react with allyl bromide introduced through a pulsed valve. These cations readily yield $\mathrm{C}_{6} \mathrm{H}_{9}^{+}$, as previously described [27].

Photodissociation experiments carried out with the 488-nm line of an Argon ion laser at powers ranging from 0.2 to $0.5 \mathrm{~W}$ are not very informative (Figure $3 \mathrm{a}$ ). The molecular ions of all $\mathrm{C}_{3} \mathrm{H}_{5} \mathrm{Br}$ isomers (1-bromopropene, 2-bromopropene, 3-bromopropene, and bromocyclopropane) photofragment readily and completely through a process similar to process 2 with photofragmentation rate constants in the range of 5 to $8 \mathrm{~s}^{-1}$ at the higher laser powers. Given these similarities, it becomes difficult to distinguish whether the data of Figure 3a are best represented by a single exponential decay or by a double exponential decay of a roughly 4:1 mixture of ion populations with similar 

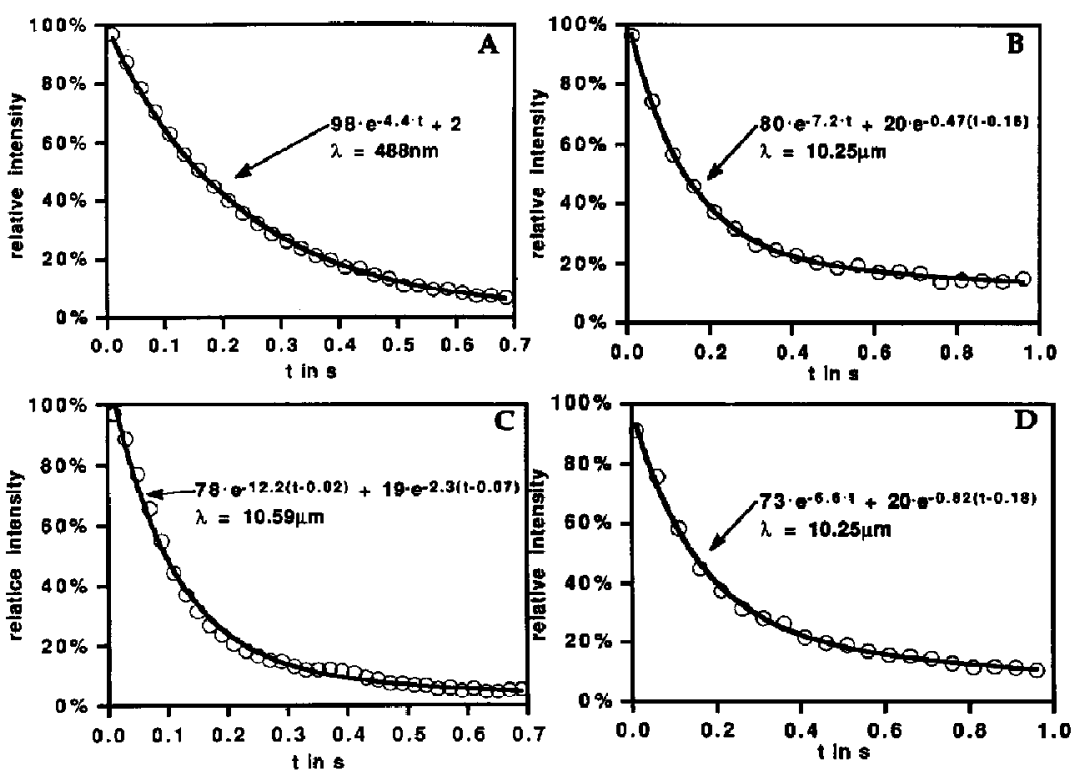

Figure 3. Photofragmentation kinetics of the 3-bromopropene molecular ion. (a) Argon ion laser at $0.5 \mathrm{~W}$. (b, c) $\mathrm{CO}_{2}$ laser at $25 \mathrm{~W} \cdot \mathrm{cm}^{-2}$ and a pressure of $6.1 \times 10^{-9}$ mbar. Different wavelengths. (d) The same, but in a mixture of 3:1 of $\mathrm{N}_{2}$ and 3-bromopropene at a total pressure of $2,4 \times 10^{-8} \mathrm{mbar}$. rate constants. An experiment performed by selecting the molecular ions remaining after ion/molecule reactions at $5 \times 10^{-8}$ mbar reveals that the unreactive ions can also be completely photodissociated by the Argon ion laser.

Our earlier experiments [25] dealing with the IR multiphoton dissociation spectra of the different $\mathrm{C}_{3} \mathrm{H}_{5} \mathrm{Br}$ molecular ions indicated that the IR photofragmentation of the molecular ion of 3-bromopropene at $10.25 \mu \mathrm{m}$ reaches an apparent constant nonzero value after 500 to $600 \mathrm{~ms}$ at laser energy densities of $25 \mathrm{~W} \cdot \mathrm{cm}^{-2}$. A more detailed study of the photofragmentation at this wavelength and at longer irradiation times suggests that the photofragmentation kinetics is best represented by a double exponential decay (Figure 3b). (The previous experiments did not recognize the fact that at the longer irradiation times the normalization must take into account the $\mathrm{C}_{6} \mathrm{H}_{9}^{+}$and $\mathrm{C}_{6} \mathrm{H}_{7}^{+}$ions that are formed from ion/molecule reactions of $\mathrm{C}_{3} \mathrm{H}_{5}^{+}$.) This is physically significant when compared with a similar

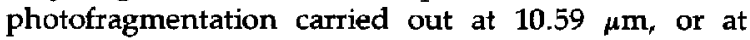
$10.67 \mu \mathrm{m}$, at similar laser power densities (Figure 3c) that can also be represented by a double exponential function with much faster rate constant for one component. These experiments indicate that this behavior cannot be simply ascribed to a nonhomogeneous ion cloud that slowly diffuses to the center of the cell and is sampled differently by the laser beam.

The IR multiphoton-induced photofragmentation in a system where the pressure was increased fourfold by admission of $\mathrm{N}_{2}$ to relax vibrationally excited species is shown in Figure $3 \mathrm{~d}$. Similar parameters as in Figure 3d are obtained for the double exponential decay, although the decay obeys perhaps a more complicated decay rate. This may indicate that the photofragmentation kinetics are not much affected by possible vibrational relaxation in this pressure range. Likewise, experiments carried out at twice the usual pressure of neat $\mathrm{C}_{3} \mathrm{H}_{5} \mathrm{Br}$ yield no significant differences, indicating that vibrational deactivation mechanisms even through resonant charge exchange reactions at longer times do not affect the relative ion populations. The pressure variations in these experiments are admittedly small and can only induce small changes in the vibrational population of ions.

The parameters obtained for the relative amounts of the ionic species necessary to fit the data shown in Figure $2 b$ and $d$ resemble very closely those obtained from the ion/molecule kinetics. Thus, the following experiment was performed: 3-bromopropene was ionized at a pressure of $6 \times 10^{-9}$ mbar, the molecular ions isolated and the pressure was increased to $3 \times$ $10^{-7}$ mbar by means of a pulsed valve; after a reaction time of $6 \mathrm{~s}$ the pressure was again reduced to $6 \times 10^{-9}$ mbar, the remaining molecular ions isolated and irradiated with the $\mathrm{CO}_{2}$ laser. The photofragmentation kinetics of these molecular ions is shown in Figure 4a.

There are several aspects of Figure $3 a$ that deserve special comments. First, the excitation of the unreactive ions yields the $\mathrm{C}_{3} \mathrm{H}_{5}^{+}$ions. In a subsequent reaction these ions form $\mathrm{C}_{6} \mathrm{H}_{9}^{+}$and $\mathrm{C}_{6} \mathrm{H}_{7}^{+}$ions (not shown in Figure $4 \mathrm{a}$ ). A rate enhancement of an ion $/ \mathrm{molecule}$ reaction by vibrational excitation has been previously reported by Bomse and Beauchamp [29], but only a few other cases have been observed in this type of experiment. The second noticeable effect is the induction time observed for the photofragmentation to yield the $\mathrm{C}_{3} \mathrm{H}_{5}^{+}$ion. Such induction times are frequently encountered for ions [30] and reflect the sequential nature of the multiphoton absorption process. The growth of the ion $\mathrm{C}_{6} \mathrm{H}_{7}^{+}(\mathrm{m} / z=79)$ at longer irradia- 
Figure 4. Photofragmentation of bromopropenes at a pressure of $5.1 \times$ $10^{-8}$ mbar. (a) Molecular ions of 3 bromopropene remaining after 6 -s reaction at a pressure of $3 \times 10^{-7}$ mbar. (b) Molecular ion of 1-bromopropene immediately after ionization.
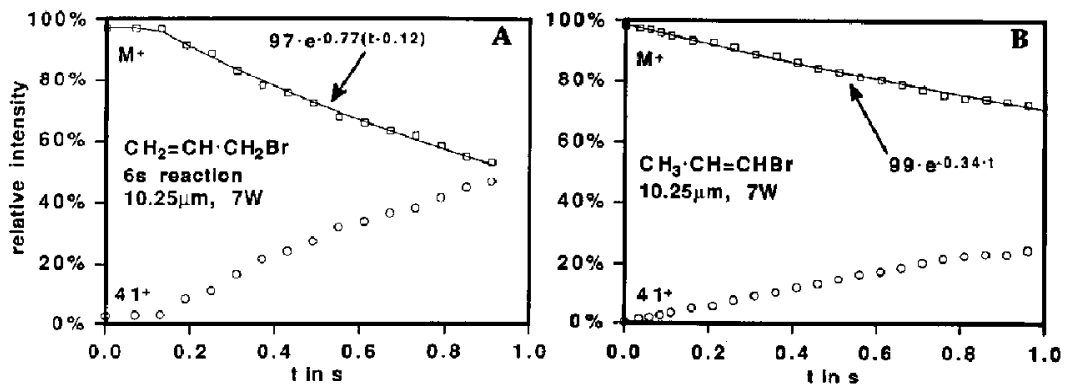

tion times is the result of both ion/molecule reactions of the $\mathrm{C}_{3} \mathrm{H}_{5}^{+}$ion and photofragmentation of the $\mathrm{C}_{6} \mathrm{H}_{9}^{+}$ ion [31].

The above experiment provides strong evidence for the presence of two isomeric ions in 3-bromopropene (a) species (I) in (82 \pm 2$) \%$ abundance corresponding to the reactive ion and strong IR absorber at $10.25 \mu \mathrm{m}$, and (b) species (II) being unreactive and slow to photofragment at $10.25 \mu \mathrm{m}$.

Because the 1-bromopropene molecular ion has been shown to be inert toward ion/molecule reactions [27] and to display an induction time for photofragmentation at wavelengths studied between $9.28 \mu \mathrm{m}$ and $10.67 \mu \mathrm{m}$ [25], a photofragmentation experiment was also carried out for 1-bromopropene at $10.25 \mu \mathrm{m}$ and a pressure of $6 \times 10^{-9} \mathrm{mbar}$. No induction timc for photofragmentation can be seen at this wavelength, as shown in Figure $4 \mathrm{~b}$. A similar experiment carried out with pure cis 1-bromopropene yields identical results. Yet a more important consideration is the fact that the laser-enhanced reaction 2 is much slower, a fact that may hide an induction time. Furthermore, the delayed appearance of the $\mathrm{C}_{6} \mathrm{H}_{9}^{+}$and $\mathrm{C}_{6} \mathrm{H}_{7}^{+}$ions (not shown in Figure 4b) demonstrates that they originate from ion/molecule reactions of the $\mathrm{C}_{3} \mathrm{H}_{5}^{+}$ion with the neutral 1-bromopropene. An experiment in which the $\mathrm{C}_{3} \mathrm{H}_{5}^{+}$ions were continuously ejected during the irradiation time confirmed unequivocally the source of these ions. It might be remembered that one isomer of 3-bromopropene photofragments at $\mathbf{1 0 . 5 9}$ $\mu \mathrm{m}$ without an induction time and with a rate constant of $12 \mathrm{~s}^{-1}$, and a second isomer with a rate constant of $2.3 \mathrm{~s}^{-1}$ and an induction time of $0.7 \mathrm{~s}$, whereas 1-bromopropene shows at this wavelength an induction time of $0.1 \mathrm{~s}$ and a rate constant of 4.7 $s^{-1}$ [25]. This set of experiments provides evidence that isomer (II) of the molecular ion of 3-bromopropene exhibits a different spectroscopic behavior than the 1-bromopropene molecular ion, because it shows a very different photofragmentation behavior as a function of wavelength. The modeling of the photofragmentation kinetics [25] by a general double exponential decay for all molecular ions (Table 1) also rules out on spectroscopic grounds the 2-bromopropene or bromocyclopropane molecular ion structure for isomer (II).
The dependence of the $10.25 \mu \mathrm{m}$ multiphoton photofragmentation on laser power densities was also verified for values ranging between $11 \mathrm{~W} \cdot \mathrm{cm}^{-2}$ to 50 $\mathrm{W} \cdot \mathrm{cm}^{-2}$. For these experiments a nonlinear regression program was used to determine the best fit for the experimental data by using two different approaches. The first procedure used a double exponential function in which the relative populations of species (I) and (II) and their rate constants were optimized for each power density. The second procedure made use of the relative populations derived from the ion/molecule kinetics $(82 \%$ for I and $18 \%$ for II) followed by optimization only for the rate constants. The rate constants calculated for species (I) are not strongly affected by the choice of optimization procedure. However, the rate constants and the exact contribution from the kinetics of (II) become more sensitive to which approach is used and to experimental errors. Thus, the actual values for the rate constants of the second species derived from a double exponential nonlinear fitting cannot be considered very reliable. (This was the reason to perform the pulsed experiment leading to the data of Figure 4a.)

The photodissociation rate constant for species (I) was found to obey the equation

$$
\begin{gathered}
k=\sigma \cdot \Phi^{n} \\
(\Phi=\text { photon flux })
\end{gathered}
$$$$
\text { ( } \sigma=\text { phenomenological absorption coefficient) }
$$

with $\mathrm{n}=1.5$. This power dependence is similar to that observed in other multiphoton-driven processes, and for the case where the rate constant measures the process under steady-state conditions it reflects the n-photon-rate-determining coherent process $[32,33]$. Values ranging from $n=2$ to $n=4$ were found for the rate constant of species (II) depending on the chosen set of values from the different methods of calculation explained above.

The data presented in this article are thus consistent with the presence of two isomeric molecular ions in 3-bromopropene in a $(4.5 \pm 0.5): 1$ ratio. The fact that similar ion populations can be derived from the ion/molecule kinetics and from collisionless IR multiphoton-induced fragmentation clearly points out that 
Table 1. Kinetics of photofragmentation of molecular ions (70 eV) from different $\mathrm{C}_{3} \mathrm{H}_{5} \mathrm{Br}$ isomers fitted to the general expression ${ }^{\mathrm{a}}$

\begin{tabular}{|c|c|c|c|c|c|c|c|c|}
\hline & $A_{1}$ & $A_{2}$ & $A_{3}$ & $T_{1}$ & $\tau_{2}$ & $k_{1}$ & $k_{2}$ & $\lambda(\mu \mathrm{m})$ \\
\hline 1-Bromopropene & 1.00 & & & & & 0.41 & & \\
\hline 2-Bromopropene & 1.00 & & & & & 0.12 & & 9.28 \\
\hline 3-Bromopropene & 0.64 & 0.36 & & & 0.53 & 7.1 & 0.28 & \\
\hline Bromocyclopropane & 0.91 & & 0.09 & & & 8.6 & & \\
\hline 1-Bromopropene & 1.00 & & & & & 0.08 & & \\
\hline 2-Bromopropene & 1.00 & & & & & 0.07 & & 9.53 \\
\hline 3-Bromopropene & 1.00 & & & & & 0.67 & & \\
\hline Bromocyclopropane & 0.95 & & 0.05 & & & 9.2 & & \\
\hline 1-Bromopropene & 1.00 & & & & & 0.34 & & \\
\hline 2-Bromopropene & 1.00 & & & & & 0.26 & & 10.25 \\
\hline 3-Bromopropene & 0.8 & 0.2 & & & 0.16 & 7.2 & 0.47 & \\
\hline Bromocyclopropane & 1.00 & & & & & 3.9 & & \\
\hline 1-Bromopropene & 0.85 & & 0.15 & 0.11 & & 5.3 & & \\
\hline 2-Bromopropene & 1.00 & & & & & 2.03 & & 10.59 \\
\hline 3-Bromopropene & 0.81 & 0.19 & & 0.02 & 0.07 & 12.2 & 2.3 & \\
\hline Bromocyclopropane & 0.84 & & 0.16 & & & 4.24 & & \\
\hline 1-Bromopropene & 1.00 & & & 0.04 & & 3.3 & & \\
\hline 2-Bromopropene & 1.00 & & & & & 1.7 & & 10.67 \\
\hline 3-Bromopropene & 0.93 & & 0.07 & & & 10.2 & & \\
\hline Bromocyclopropane & 1.00 & & & & & 2.2 & & \\
\hline
\end{tabular}

the isomerization process occurs in the ionization process and not by collisions.

Preliminary calculations at the semi-empirical level [34], using the AM1 method [35], predict that 3bromopropene may exist in lower energy structures obtained by elongation of the carbon-bromine bond. One of these structures corresponds to a symmetric bromonium-type ion structure with the $\mathrm{Br}$ straddling carbons 1 and 3 . The other predicted low energy form corresponds to an asymmetric structure with the $\mathrm{Br}$ atom out of the carbon plane. It is particularly interesting that rearrangement to these structures is calculated to involve a very low barrier, and that the calculated charge distribution makes these species to be better represented by a loose ion-neutral complex, $\mathrm{C}_{3} \mathrm{H}_{5}^{+}\left(\mathrm{Br}{ }^{*}\right)$. Such a structure is particularly attractive to explain the resemblance between the ion/molecule reactions of species (I) of the molecular ion and the $\mathrm{C}_{3} \mathrm{H}_{5}^{+}$ion. Structures similar to those advocated here have been previously postulated to account for the isomers of the benzyl chloride parent ions [20], which find some support in the infrared spectra of such ions in solid matrices [36]. The alternative stable structures encountered in some ethyl halides ( $\mathrm{Cl}, \mathrm{F}$ ) [37], which would correspond to a $\left(\mathrm{C}_{3} \mathrm{H}_{4} \mathrm{BrH}^{+}\right.$.) structure, are likely to involve higher energies for this case. The preliminary structures proposed from these calcula- tions must be viewed with caution as the adequacy of the parameterization for open shell cations of this type may be questionable. More rigorous calculations are presently under way to help elucidate the nature of species (I) and (II) observed for the molecular ion of 3-bromopropene.

The results and conclusions of this work represent an example of how the combination of wavelength dependence IR multiphoton-induced fragmentation and photofragmentation kinetics can provide a powerful approach toward the characterization of the structure of ions.

\section{Acknowledgments}

The authors acknowledge the support of the Swiss National Science Foundation, the Federal Commission for the Encouragement of Research, and Spectrospin, Fallanden. We also thank the support of the São Paulo Science Foundation, FAPESP, the BID-USP program, and the Brazilian Research Council, CNPq. We thank S. Haebel for help with operation of the Spertrospin spectrometer and A. Heusler for preparation of the samples.

\section{References}

1. See Ion and Cluster Ion Spectroscopy and Structure; Maier, J. P., Ed.; Elsevier: Amsterdam, 1989, for a recent outlook on this problem. 
2. Hehre, W. J.; Radom, L.; Schleyer, P. v. R.; Pople, J. A. Ab Initio Molecular Orbital Theory; John Wiley: New York, 1986.

3. Radom, L.; Bouma, W. J.; Nobes, R. H.; Yates, B. F. Pure \& Appl. Chem. 1984, 56, 1831-1842.

4. Levsen, K.; Schwarz, H. Angetw. Chem, 1976, 88, 589-620.

5. McLafferty, F. W.; Bockoff, F. M. I. Am. Chem. Soc. 1979, 101, 1783-1786.

6. Dill, J. D.; McLafferty, F. W. J. Am. Chem. Soc. 1979, 101 , 6526-6530.

7. Bass, L. M.; Bowers, M. T. Org. Mass Spectrom. 1982, 17, 229-236.

8. Lias, S. G.; Bartmess, J. E.; Liebman, J. F.; Holmes, J. L.; Levin, R. D.; Mallard, G. W. I. Phys. Chem. Ref. Data 1988, 17, Suppl. 1.

9. Bouma, W. J.; MacLeod, J. K.; Radom, L. I. Am. Chem. Soc. 1982, 104, 230-231.

10. Holmes, J. L.; Lossing, F. P.; Terlouw, J. K.; Burgers, P. C. J. Atn. Chem. Soc. 1982, 104, 231-232.

11. Hammertum, S. Mass Spectrom. Rev. 1988, 7, 231-232.

12. Shao, J.-D.; Baer, T.; Morrow, J. C.; Fraser-Monteiro, M. L. J. Chem. Phys. 1987, 87, 5242-5250.

13. McAdoo, D. J. Mass Spectrom. Rev. 1988, 7, 363-393.

14. Jackson, J.-A.; Lias, S. G.; Ausloos, P. J. Am. Chem. Soc. 1977, 99, 7515-7521.

15. Ausloos, P. J.; Lias, S. G. I. Am. Chem. Soc. 1981, 103, 6505-6507.

16. Durbar, R. C. In Gas Phase Ion Chemistry, Vol. 3; Bowers, M. T., Ed.; Academic: London, 1984; pp. 130-166.

17. Thorne, L. R.; Beauchamp, J. L. In Gas Phase Ion Chemistry, Vol. 3; Bowers, M. T., Ed.; Academic: London, 1984; pp. 168-211.

18. Orth, R. G.; Dunbar, R. C. I. Am. Chem. Soc. 1978, 100, 5949-5950; Orth, R. G.; Dunbar, R. C. J. Am. Chem. Soc. 1982, 104, 5617-5621.
19. Dunbar, R. C.; Fitzgerald, G. B.; Hays, J. D. Int. I. Mass Spectrom. Ion Proc. 1985, 66, 313-326.

20. Honovich, J. P,; Dunbar, R. C. Int. I. Mass Spectrom. Ion Phys. 1982, 42, 33-42.

21. van Velzen, P. N. T.; van der Hart, W. J. Org. Mass Spectrom. 1984, 19, 190-192.

22. van der Hart, W. J. Org. Mass Spectrom. 1988, 23, 187-190.

23. Bensimon, $M_{1}$; Zhao, G.; Gäumann, T. Spectros. Int. I. 1989, 7, 193-196; Bensimon, M.; Gäumann, T.; Zhao, G. Int. J. Mass Spectrom. Ion Proc. 1990, 100, 595-609.

24. Riveros, J. M.; Galembeck, S. E. Int. J. Mass Spectrom. Ion Proc. 1983, 47, 183-186.

25. Gäumann, T.; Riveros, J. M.; Zhu, Z. Helv. Chim. Acta 1990, 73, 1215-1218.

26. Marshall, A. G.; Lin Wang, T,-C.; Ricca, T. L. J. Am. Chem. Soc. 1985, 107, 7893-7897.

27. Gäumann, T.; Zhu, Z.; Kida, M. C.; Riveros, J. M. Helv. Chint. Acta 1990, 73, 2218-2224.

28. Worrell, C. W. J. Electron Spectros. Relat. Phenom. 1974, 3, 359-367.

29. Bomse, D. S.; Beauchamp, J. L. J. Am. Chem. Soc. 1980, 102, 3967-3969.

30. Bensimon, M.; Rapin, J.; Gäumann, T. Int. J. Mass Spectrom. Ion Proc. 1986, 72, 125-135.

31. Gäumann, T.; Riveros, J. M.; Zhu, Z. unpublished results.

32. Quack, M. I. Chem. Phys. 1978, 69, 1282-1307.

33. Lupo, D. W.; Quack, M. Chem. Rev. 1987, 87, 181-216.

34. Carrupt, P.; Riveros, J. M.; Stahl, D. Private communication.

35. Dewar, M. J. S.; Zoebisch, E. G.; Healy, E. F.; Stewart, J. P. P. J. Am. Chem. Soc. 1985, 107, 3902-3909.

36. Keelan, B. W.; Andrews, L. J. Am. Chem. Soc. 1981, 103, $822-829$.

37. Blanchette, M. C.; Holmes, I. L.; Lossing, F. P. Org. Mass Spectrom. 1987, 22, 701-709. 